\title{
Preface to Abridged Edition
}

\begin{abstract}
A
$s$ STUDENTS in rapidly increasing numbers have become interested in the study of anthropology, anthropologists have become increasingly concerned with developing the teaching of anthropology. One step in that development was the Educational Resources in Anthropology (ERA) project at the University of California, Berkeley, which was supported by the National Science Foundation. The results of that project appeared in 1963 in two volumes, The Teaching of Anthropology and Resources for the Teaching of Anthropology. The two books have been extensively used, not only by teachers but also by undergraduate and graduate students for whom the articles provided a useful survey of salient aspects of the subject.

The present paperbound edition of The Teaching of Anthropology is intended to make a number of articles in the original volume available to students and general readers. Since this edition had to be an abridged version, the editors asked the authors who had contributed to the main volume to indicate their opinions as to which articles were best suited for a wider audience. Guided by their responses, the editors made the selections for this edition. Of the forty-six articles in the original volume, twenty-six are reprinted in this edition. A number of those which could not be included because of their more specialized focus are notable contributions to the field and all who have more than a passing interest in anthropology should refer to them in the original publication.

Every article appears here as it did in the original edition. 'The editors' introductory remarks to the sections have been slightly revised to accord with the modifications of the sections. Each of the papers was originally presented before one of ten symposia arranged under the auspices of the ERA project. Each was discussed there and then revised by the author in the light of the discussion and subsequent correspondence. While the flow of correspondence and of editors' memoranda may have
\end{abstract}


influenced the final version, each author wrote on the subject he wanted to cover in his own style and expressed his own views.

We note again our thanks to the two officers of the Course Content Improvement Section of the National Science Foundation, Richard E. Paulson and Charles A. Whitmer, who fostered the ERA project. Pro fessor Leslie White gave it encouragement as our liaison with the Executive Board of the American Anthropological Association. Valuable aid was given by Theron A. Nunez Jr., Kenneth A. R. Kennedy, Lewis L. Klein, Paul Hockings, and Zenon S. Pohorecky; all were graduate students at the time of their work on the project. Our colleagues in the Department of Anthropology at Berkeley have been most helpful in their suggestions and support.

The Wenner-Gren Foundation not only made possible the International Symposium, but its late President, Dr. Paul Fejos, and its Director of Research, Lita Osmundsen, contributed wonderfully to its spirit. They command our warm appreciation.

Our reliance on our secretaries was great as is our debt and thanks to them. Miss Dorothy Szorc was editorial secretary; Mrs. Alice Davis as project secretary was with the project from its beginnings and helped us through every stage of its work.

David G. Mandelbaum

Gabriel W. LASKer

Ethel M. Albert 